\title{
Urban Heat Island Effect: It's Relevance in Urban Planning
}

\section{Bhargava $A^{1^{*}}$, Lakmini $S^{2}$ and Bhargava $S^{3}$}

${ }^{1}$ Department of Civil Engineering, Global Institute of Engineering and Technology, Hyderabad, India

${ }^{2}$ Department of Town and Country Planning, University of Moratuwa, Moratuwa, Sri Lanka

${ }^{3}$ Sustainable Environmental Design (SED), AA School of Architecture, London, UK

\begin{abstract}
The rapid growth of urbanization leads to the cumulative effect of all the negative impacts in the form of pollution, production of waste heat from human activity, multiple diseases, water stress, and so on so forth. With the development or expansion of cities and towns significant vegetation is lost along with urban surfaces are paved or covered with buildings resulting into less shade and moisture to keep urban areas cool. It reveals the fact that Built-up areas evaporate less water resulting into elevated surface and air temperatures of the cities. The amount of urban heat island effect is experienced based on properties of urban materials which consist of solar reflectance, thermal emissivity and heat capacity along with ability to reflect, emit and absorb the suns energy. These conceptual issues lead to warming of urban areas as compared to their rural surroundings, a phenomenon known as the "heat island effect." An effort has been made in the present paper by the authors to describe the effect of heat island effect on urban environment and its planning. An effort has also been made to suggest mitigating measures to combat heat island effects in urban areas.
\end{abstract}

Keywords: Urban heat island; Urban planning; Thermal emissivity

\section{Introduction}

With the rapid growth of population, urbanization is gaining momentum where urban areas are developed with greater proportion resulting into changes in existing landscape, buildings, roads, and other supporting infrastructure. Such a change replaces open land and vegetation in the form of permeable surfaces with concrete surfaces which are impermeable and dry in nature. Such a development leads to the formation of urban heat islands whereby urban regions experience warmer temperatures than their adjacent rural surroundings. The present paper focus on an overview of different types of urban heat islands along with factors causing them and identifying broad conceptual components to mitigate the alarming effect of heat island.

It has been seen that many urban areas experience higher temperatures as compared to their rural surroundings thereby constituting an urban heat island. It has been reported that annual mean air temperature of a city with one million or more people can be $1.8-5.4^{\circ} \mathrm{F}\left(1-3^{\circ} \mathrm{C}\right)$ warmer than its surroundings and interestingly on a clear, calm night with negligible winds, this temperature difference can be as much as $22^{\circ} \mathrm{F}\left(12^{\circ} \mathrm{C}\right)$ [1]. Moreover, roof and pavement surface temperatures can be $50-90^{\circ} \mathrm{F}\left(27-50^{\circ} \mathrm{C}\right)$ hotter than the ambient air on a hot sunny summer day while shaded or moist surfaces in rural surroundings remain close to air temperatures [2]. Such a phenomenon is known as surface urban heat islands which ultimately may contribute to atmospheric urban heat islands. Further, air temperatures particularly after sunset in cities, can be as high as $22^{\circ} \mathrm{F}\left(12^{\circ} \mathrm{C}\right)$ warmer than the air in less developed neighboring regions [3]. The corresponding author of the present paper has carried out a study of heat island for the city of Jaipur, India in which it has been observed that the temperature difference between urban city and open green area was to the tune of $15^{\circ} \mathrm{C}$ as a result of which significant energy consumption was noticed.

\section{Defining of Urban Heat Island}

Urbanization and industrialization are main route causes of Urban Heat Island phenomena. Many urban areas are experiencing elevated temperature compare to their rural fringe at night. Elevated temperature in urban area surrounded by cool temperature is like an island which is called as urban heat island, the schematic picture of which is reflected in Figure 1 [4].

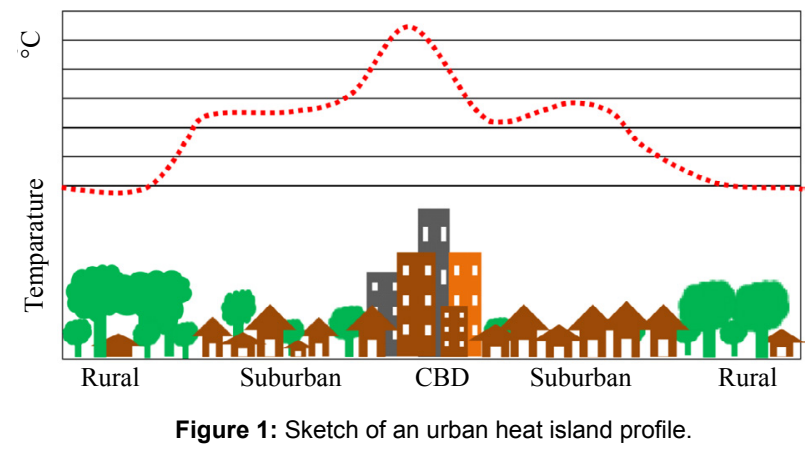

Urban Heat Island is classified into two types, namely, Surface Urban Heat Island and Atmospheric Urban Heat Island. Surface Urban Heat Island is a phenomenon where surfaces like roofs, pavements are heated on day time. Urban surfaces are more exposed to sun compare to shaded surfaces in rural areas. Though Surface Urban Heat Island is seen at day and night both but it is highest during day time. When urban air gets warmer than the adjacent rural air temperature, it defines as Atmospheric Urban Heat Island which is further divided in two subdivisions in the form of Canopy Layer Urban Heat Island and Boundary Layer Urban Heat Island. Canopy Layer Urban Heat Island Heat Island forms from the ground to below the tops of trees or roofs whereas Boundary Layer Urban Heat Island start from the roof top or tree top level and extend up to the point where urban landscape no longer influence the atmosphere. However, Surface Urban Heat Island

${ }^{*}$ Corresponding author: Akshey Bhargava, Department of Civil Engineering, Global Institute of Engineering and Technology, Hyderabad, India, Tel: +91-9985359-601; E-mail: draksheyb@gmail.com

Received April 24, 2017; Accepted May 26, 2017; Published June 02, 2017

Citation: Bhargava A, Lakmini S, Bhargava S (2017) Urban Heat Island Effect: It's Relevance in Urban Planning. J Biodivers Endanger Species 5: 187. doi: 10.4172/2332-2543.1000187

Copyright: @ 2017 Bhargava A, et al. This is an open-access article distributed under the terms of the Creative Commons Attribution License, which permits unrestricted use, distribution, and reproduction in any medium, provided the original author and source are credited. 
Citation: Bhargava A, Lakmini S, Bhargava S (2017) Urban Heat Island Effect: It's Relevance in Urban Planning. J Biodivers Endanger Species 5: 187. doi: $10.4172 / 2332-2543.1000187$

is typically influence to increase Atmospheric Urban Heat Island as surface and canopy layers are very close to each other the basic characteristics of surface and atmospheric urban heat island is reflected in Table 1.

\section{Thermodynamics of the UHI}

The surface energy balance is composed of radiative and nonradiative component [3]. Incoming and outgoing short wave and long wave radiations are identified as radiative component. Sensible heat flux, latent heat flux and change in energy storage in water are identified as non-radiative component.

The incoming energy flux consist of net effect of incoming and outgoing long and short wave radiation:

$\mathrm{Q}^{*}=\left(\mathrm{S}_{\mathrm{o}}+\mathrm{S}_{\mathrm{i}}\right)+\left(\mathrm{L}_{\mathrm{o}}+\mathrm{L}_{\mathrm{i}}\right)$

Where,

$\mathrm{Q}^{*}=$ Incoming energy flux;

$\mathrm{S}_{\mathrm{i}}=$ Short wave radiation reflected by surface;

$\mathrm{S}_{\mathrm{o}}=$ Incoming sort wave from sun;

$\mathrm{L}_{\mathrm{o}}=$ Long wave radiation reflected and emitted by surface;

$\mathrm{L}_{\mathrm{i}}=$ Incoming long wave radiation from clouds and atmosphere.

The sum of the incoming radiation and outgoing radiation is the basic primary energy balance at the urban surface. The down welling radiation has been described as a direct heating radiation. The up welling radiation has two components. They are the reflected short wave radiation and the re-radiated long wave radiation. The up welling radiation has an important role in decreasing urban temperature with regards to the non-radiative components in the UHI, the sensible heat flux and the latent heat flux are two major factors.

Understanding of energy transfer mechanism is very important to mitigate UHI and design proper urban form. Light energy is converted in to thermal energy at UI process, which contributes to elevated temperature in urban areas. Energy transaction is take place in three ways between materials as:

- Convection: The transfer of heat by tem tin of a fluid.

- Conduction: The transfer and distribution of heat energy from atom to atom within substance.

- Radiation: The direct transport of energy through space without any kind of matter [5].

\section{Urban Planning Contribute to UHI}

While many factors contribute to the formation of UHI, Urban Planning aspects are related to both the intrinsic nature of the city, such as its size, population, building density and land uses and external factors such as climate, weather and seasons [4].

\section{Urban geometry}

Urban Geometry reflects the dimensions and spacing of buildings within a city where it influences on the energy balance. Energy absorption, along with ability to emit long wave radiation back to space coupled with influencing wind flow as urban areas are full of buildings and erected objects. If these buildings have been built against wind flow it contributes to reduce wind velocity and elevate the temperature further and further. Another factor is Absence of sufficient space between buildings to circulate wind. On the other hand urban canopy is a property of an urban geometry. Cities comprise with multilayer buildings. The heat reflected by small buildings is trapped by neighboring taller buildings and store heat in the air without reflects to space [6].

\section{Land use pattern}

Urban vegetation is replaced by buildings, pavement, roads and many other structures leading to less vegetation cover. Natural features can retain thermal energy by evapotranspiration which can reduce the amount of thermal energy reaching to surface and emitted in to atmosphere. Rural areas have more vegetation and natural features to evaporate more water in to atmosphere to keep it cool. As a result of ad hoc developments take place in cities compare to rural areas, evaporation is absence in cities. Highly developed areas have high runoff rate and very low infiltration rate due to impervious surfaces resulting into less moisture available for evapotranspiration as compared to natural ground cover. This characteristic contributes to higher surface and air temperatures in urban areas. Each $10 \%$ vegetative cover can reduce the temperature $0.6 \mathrm{~K}$ and commented that trees can reduce the effect substantially [3].

\section{Properties of urban materials}

Solar energy comprises with Infrared (52\%), Visible Light (43\%) and Ultra Violet rays (5\%). All of these energy types contribute to UHI. Property of urban materials effect on the determination of albedo. Albedo is the ratio between incident solar energy and reflected solar energy. It is good to have high albedo. Albedo is depending on arrangement of surfaces, material, pavements and color.

$$
\text { Albedo }=\frac{\text { Reflected energy }}{\text { Incident energy }}
$$

\begin{tabular}{|c|c|c|}
\hline Feature & Surface Urban Heat Island & Atmospheric Urban Heat Island \\
\hline Temporal Development & $\begin{array}{l}\text { - Present at all time of the day and night. } \\
\text { - Most intense during the day and in the summer. }\end{array}$ & $\begin{array}{l}\text { - May be Smaller or non-exist during the day time. } \\
\text { Most intense at night or predawn and in the } \\
\text { winter. }\end{array}$ \\
\hline $\begin{array}{l}\text { Peak Intensity (most intense UHI } \\
\text { conditions) }\end{array}$ & $\begin{array}{l}\text { More spatial and temporal variation: } \\
\text { - } \quad \text { Day: } 18-27^{\circ} \mathrm{F}\left(10-15^{\circ} \mathrm{C}\right) \\
\text { - } \quad \text { Night: } 9-18^{\circ} \mathrm{F}\left(5-10^{\circ} \mathrm{C}\right)\end{array}$ & $\begin{array}{l}\text { Less variation: } \\
\text { - } \quad \text { Day: } 1.8-5.4^{\circ} \mathrm{F}\left(-1-3^{\circ} \mathrm{C}\right) \\
\text { - Night: } 12.6-21.6^{\circ} \mathrm{F}\left(7-12^{\circ} \mathrm{C}\right)\end{array}$ \\
\hline Typical Identification Method & $\begin{array}{l}\text { Indirect measurement } \\
\text { - } \quad \text { Remote sensing. }\end{array}$ & $\begin{array}{l}\text { Direct measurement } \\
\text { - } \quad \text { Fixed weather statins. } \\
\text { - } \quad \text { Mobile traverses. }\end{array}$ \\
\hline Typical Depiction & Thermal images & $\begin{array}{l}\text { - Isotherm maps. } \\
\text { - Temperature graph. }\end{array}$ \\
\hline
\end{tabular}

Table 1: Basic characteristics of surface and atmospheric urban heat island 
Albedo is correlated with color of materials. Light color materials have less energy absorption capacity and high albedo. There for contribution to UHI is less. Dark color materials have high absorption capacity during day time and high reflectance at night. Normally urban areas have dark surfaces which have less albedo [7].

Thermal emittance is also another important factor. Ability of surfaces to emit infrared radiation identified as thermal emittance. Surfaces which have high emittance value will release more heat and remain cool. Many construction materials except metal have high thermal emittance value. The radiative properties of different materials are given in Table 2.

The next important property is heat capacity which in reality reflects ability to store heat. Many urban construction materials have high heat capacity compare to rural material such as steel, stone. As these materials have high heat capacity they typically contribute to UHI. The physical properties of different materials have been shown in Table 3.

\section{Effects of UHI}

Higher temperatures on account of urban heat islands, particularly during the summer, can affect environment and quality of life. However, some impacts may be beneficial as they lengthen the plant-growing season, but majority of them are negative. These negative impacts include:

- Increased energy consumption.

- Elevated emissions of air pollutants and greenhouse gases.

- Compromised human health and comfort.

- Impaired water quality.

- Urban Heat Island has both direct and indirect impact including social, economic and environment.

\section{Increased energy consumption}

Higher demand on energy for air condition during summer time due to UHI is significant impact. The demand for electricity rises up from $2-4 \%$ for every $1^{\circ} \mathrm{C}$ rise in temperature. According to U.S. Department of Energy (1996) one sixth of the electricity in the U.S. is consumed to cool building at an annual cost of $\$ 40$ billion. Mitigation plan for the UHI could save approximately $\$ 10$ billion in annual energy cost. Usage of air condition reversely contributes to increase UHI phenomena. Air conditions absorb inside heat and release to outside [8-12].

\begin{tabular}{|c|c|c|}
\hline Material & Albedo( $\boldsymbol{\alpha})$ & Emissivity( $\boldsymbol{\varepsilon})$ \\
\hline Asphalt & $0.05-0.20$ & 0.95 \\
\hline Concrete & $0.10-0.35$ & $0.71-0.91$ \\
\hline Urban Areas & $0.10-0.27$ & $0.85-0.96$ \\
\hline Soil: Wet to Dry & $0.05-0.40$ & $0.98-0.90$ \\
\hline Grass: Long t Short & $0.16-0.26$ & $0.90-0.95$ \\
\hline
\end{tabular}

Table 2: Radiative properties of several materials [2]

\begin{tabular}{|c|c|c|c|}
\hline Material & Density( $\mathbf{\sigma}) \mathbf{~ k g / \mathbf { m } ^ { 3 }}$ & $\begin{array}{c}\text { Heat Capacity(C) } \\
\mathbf{J} / \mathbf{m}^{\mathbf{3}} / \mathbf{K}\end{array}$ & $\begin{array}{c}\text { Thermal } \\
\text { Conductivity(k) } \\
\mathbf{W} / \mathbf{m} / \mathbf{k}\end{array}$ \\
\hline Dry Clay Soil & $1.60 \times 10^{3}$ & 1.42 & 0.25 \\
\hline $\begin{array}{c}\text { Saturated Clay } \\
\text { Soil }\end{array}$ & $2.00 \times 10^{3}$ & 3.10 & 1.58 \\
\hline Asphalt & $2.11 \times 10^{3}$ & 1.94 & 0.75 \\
\hline Dense Concrete & $2.40 \times 10^{3}$ & 2.11 & 1.51 \\
\hline
\end{tabular}

Table 3: Physical properties of several materials [2].
The higher temperatures due to heat island in cities increase energy consumption for cooling. It has been reported that electricity demand for cooling increases $1.5-2.0 \%$ for every $1^{\circ} \mathrm{F}\left(0.6^{\circ} \mathrm{C}\right)$ increase in air temperatures which reflect increase in energy demand to the extent of $5-10 \%$ as a result of heat island effect which is quite significant [13].

\section{Elevated emissions of air pollutants and greenhouse gases}

When the demand on energy is high, it would lead to high production of energy resulting into increase use of fossil fuel for energy production. Combusting fossil fuel emit pollutants to the air such as Sulfur Dioxide $\left(\mathrm{SO}_{2}\right)$, Nitrogen Oxides $\left(\mathrm{NO}_{x}\right)$, Carbon Monoxide, Carbon Dioxide $\left(\mathrm{CO}_{2}\right)$, and Mercury $(\mathrm{Hg})$ where in $\mathrm{CO}_{2}$ contribute to greenhouse effect which leads to global warming along with contributing to acid rain, smog [14].

Besides, Ground level Ozone $\left(\mathrm{O}_{3}\right)$ formation is another problem which takes place when $\mathrm{NO}_{\mathrm{x}}$ and Volatile Organic Compounds (VOCs) react in the presence of sunlight. In Los Angeles, the concentration of $\mathrm{O}_{3}$ is often $240 \mathrm{ppb} \mathrm{v}^{2}$ at $32^{\circ} \mathrm{C}$ while its National Ambient Air Quality Standard (NAAQS) is $120 \mathrm{ppb}$ v. Due to increase in energy demand, more fossil fuel is consumed in power plants which emit following air pollutants into air:

- Sulfur dioxide $\left(\mathrm{SO}_{2}\right)$.

- Nitrogen oxides (NOx).

- Particulate matter (PM).

- Carbon monoxide (CO).

- $\operatorname{Mercury~(Hg)}$.

The air pollutants referred to above are harmful to human health and also lead to complex air quality problems such as the formation of ground-level ozone (smog), fine particulate matter, and acid rain. The Increase use of fossil-fuel-in powered plants contribute greenhouse gases, such as carbon dioxide $\left(\mathrm{CO}_{2}\right)$ thereby leading to global climate change.

\section{Water quality}

Excess temperature contain in the surfaces likes pavements and roof transfer into storm water during rain thereby water temperature increases which affects directly to metabolism and reproduction of many aquatic species. Tests have shown that pavements that are $100^{\circ} \mathrm{F}\left(38^{\circ} \mathrm{C}\right)$ can increases initial rainwater temperature from roughly $70^{\circ} \mathrm{F}\left(21^{\circ} \mathrm{C}\right)$ to over $95^{\circ} \mathrm{F}\left(35^{\circ} \mathrm{C}\right)$. This heated storm water generally becomes runoff and is released into streams, rivers, ponds, and lakes thereby affect all aspects of aquatic life, especially the metabolism and reproduction of many aquatic species. Rapid temperature changes in aquatic ecosystems resulting from warm storm water runoff can be particularly stressful and even fatal to aquatic life [15-18].

\section{Adverse health impact}

Increase in air temperature and air pollution effects human health by different ways such as discomfort, respiratory difficulties, heat cramps, non-fatal heat stroke and heat related mortality. Children and adults are more vulnerable for heat related mortality. The Center for Disease Control estimates that from 1979 to 1999, excessive heat exposure contributed to more than 800 premature deaths in the United States (http://www.bt.cdc.gov/).

\section{Mitigative Measures to Restrict Heat Island}

The Urban Heat Island effect can be mitigated by conceptualising the urban planning and strategy for urban development in the form of following: 
Citation: Bhargava A, Lakmini S, Bhargava S (2017) Urban Heat Island Effect: It's Relevance in Urban Planning. J Biodivers Endanger Species 5: 187. doi: $10.4172 / 2332-2543.1000187$

Page 4 of 4

- Optimization of concreting to non-concreting of urban surface areas through well-defined simulation models.

- Optimization of vertical to horizontal expansion of city or urban area through well-defined simulation models.

- Conceptual urban planning having regard aero-dynamics of the region.

- Ensuring and maintaining the air Ventilation of urban area.

- Balancing Albedo Effect in urban area.

- Scientific planning and development of green belt or green cover in urban area having regard to aero-dynamics of the region.

- Installation of green roof in buildings in the urban area which include development of plants and vegetation to harness evaporative cooling thereby restricting heat island.

- Installation of Sprinklers on the roof to wet the surface so that the air around it cools through evaporation.

- Planning and development of green buildings in the urban area.

- Reduction of albedo factor of asphalt by application of high reflectivity coatings to asphalt.

- Paintings of structures with white or other light colors to make its surface more reflective.

\section{Conclusion}

Urban heat island and its effect is assuming greater concern with the rapid growth of urbanization. It has multidimensional impacts including increase in energy consumption, adverse health impacts, air and water pollution, and so on so forth. It is required to be effectively addressed by the urban planners and all mitigating measures of which some are reflected in the present paper are to be taken to effectively mitigate urban heat island effect.

\section{References}

1. Oke TR (1997) Urban climates and global environmental change. Appl Climatol Principles Pract pp: 273-287.
2. Oke TR (1987) Boundary Layer Climates. NY, USA: Routledge.

3. Oke TR (1982) The Energetic basis of the urban heat Island. Q J R Meteorol Soc 108: 1-24.

4. Roth M, Oke TR, Emery WJ (1989) Satellite-derived urban heat islands from three coastal cities and the utilization of such data in urban climatology. Int $J$ Remote Sensing 10: 1699-1720.

5. Berdahl P, Bretz S (1997) Preliminary survey of the solar reflectance of coo roofing materials. Energy and Buildings 25: 149-158.

6. Voogt JA, Oke TR (2003) Thermal remote sensing of urban areas. Remote Sensing of Environment. 86: 370-384.

7. Christen A, Vogt R (2004) Energy and radiation balance of a central European city. Int J Climatol 24: 1395-1421.

8. Sailor DJ, Fan H (2002) Modeling the diurnal variability of effective Albedo for cities. Atmos Environ 36: 713-725.

9. Voogt J (2002) Urban heat Island. EGEC 3.

10. http://www.osti.gov/bridge/servlets/purl/860475-UIHWlq/860475.PDF

11. Sailor DJ (2002) Urban heat Islands, opportunities and challenges for mitigation and adaptation. Sample electric load data for New Orleans, LA (NOPSI, 1995) North American Urban Heat Island Summit.

12. Taha H, Kalkstein LS, Sheridan SC, Wong E (2004) The potential of urban environmental controls in alleviating heat-wave health effects in five US regions. Presented at the American Meteorological Society Fifth Conference on Urban Environment.

13. Kalkstein LS, Sheridan SC (2003) The impact of heat Island reduction strategies on health-debilitating oppressive air masses in Urban areas. Prepared for U.S. EPA Heat Island Reduction Initiative.

14. Kalkstein LS (1991) A New Approach to Evaluate the Impact of Climate upon Human Mortality. Environmental Health Perspectives 96: 145-150.

15. http://www.bt.cdc.gov/disasters/extremeheat/heat_guide.asp

16. Roa Espinosa A, Wilson TB, Norman JM, Johnson K (2003) Predicting the impact of urban Development on stream temperature using a Thermal Urban Runoff Model (TURM). National Conference on Urban Stormwater: Enhancing Programs at the Local Level.

17. http://www.epa.gov/nps/ natlstormwater03/31Roa.pdf

18. Environmental Protection Agency (EPA) (2003) Beating the heat: Mitigating thermal impacts. Nonpoint Source News-Notes 72: 23-26. 